\title{
Sepsis neonatal precoz causada por transmisión vertical de Morganella morganii, en un embarazo de término
}

\author{
Alfredo 0 valle ${ }^{1}$, M Angélica Martínez ${ }^{2}$, Elena Kakarieka³, \\ Mirna G arcía $^{1}$, Abril Salinas ${ }^{1}$. \\ Fatal neonatal sepsis caused by \\ vertical transmission of Morganella \\ morganii. Report of one case
}

We report a term neonate who developed early-onset sepsis due to Morganella morganii. The child was vaginally delivered after a short labor, and presented signs of perinatal asphyxia. Blood cultures taken soon after birth and from mother's lochia were positive for this microorganism. The infection was unresponsive to treatment with cefotaxime, to which the microorganism was susceptible, and the infant died at 17 days of age. M morganii is an opportunistic and uncommon pathogen, causing disease mainly in patients with underlying illness or after surgery. It is a rare perinatal pathogen, causing severe disease in premature infants, in association with maternal chorioamnionitis and premature rupture of the membranes (Rev Méd Chile 2009; 137: 1201-4).

(Key words: Cefotaxime; Morganella morganii; Sepsis)

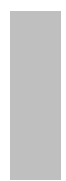

Recibido el 22 de enero, 2009. Aceptado el 25 de junio, 2009.

${ }^{1}$ Servicio y Departamento de Obstetricia, Ginecología y Neonatología, Hospital San Borja Arriarán, Facultad de Medicina, Universidad de Chile. ${ }^{2}$ Programa de Microbiología, I.C.B.M., Facultad de Medicina, Universidad de Chile. ${ }^{3}$ Servicio de Anatomía Patológica, Hospital San Borja Arriarán.

$\mathrm{M}$ organella morganii, tribus Proteeae, familia Enterobacteriaceae, es un patógeno oportunista que forma parte de la microbiota intestinal normal del ser humano ${ }^{1}$. Es causa relativamente infrecuente de enfermedad, siendo aislada principalmente en infecciones del adulto: urinarias, de piel, de tejidos blandos, neumonía y sepsis ${ }^{2-4}$. Los factores

Correspondencia a: Dr. Alfredo Ovalle S. Servicio de Obstetricia, Ginecología y Neonatología. Hospital San Borja Arriarán. Santa Rosa 1257, Santiago, Chile. Fax: 562 5555535. E mail: alfredoovalle@gmail.com predisponentes más importantes son la edad avanzada, cirugía previa y enfermedades debilitantes como diabetes, neoplasias, infección por VIH/SIDA ${ }^{2-4}$.

M morganii se ha asociado con infección perinatal en baja frecuencia. La mayoría de los casos descritos en la literatura corresponden a infecciones neonatales graves de inicio precoz, neumonías y sepsis, con el antecedente de parto prematuro $^{5-11}$ y especialmente con rotura prematura de membranas ${ }^{5-10}$. En la generalidad de las situaciones la madre tiene corioamnionitis clínica ${ }^{5-}$ 7,10. Aún más infrecuente es la sepsis neonatal al término de la gestación ${ }^{12}$. 
Presentamos un caso de sepsis neonatal precoz por M morganii, en un embarazo de término, sin rotura prematura de membranas y sin corioamnionitis clínica, que condujo a la muerte del neonato.

\section{Caso clínico}

Primigesta de 15 años de edad, con gestación de 40 semanas, que ingresó al Servicio de Obstetricia y Ginecología del Hospital Clínico San Borja Arriarán el día 11 de mayo de 2008, a las 05:40 h por presentar trabajo de parto en fase de dilatación rápida $(5 \mathrm{~cm}$ de dilatación) y expulsión de líquido amniótico (LA) con tinte meconial. Tuvo una rotura precoz de membranas 1 h 20 min antes del ingreso.

El embarazo fue controlado regularmente en el Consultorio de Maipú y fue considerado como fisiológico. Al ingreso, la paciente estaba afebril, normotensa y pulso de 80 por min. En el examen obstétrico se encontró $5 \mathrm{~cm}$ de dilatación, presentación cefálica apoyada, membranas rotas, LA con tinte meconial y latidos cardiofetales (LCF) normales. No se solicitaron exámenes hematológicos para pesquisar infección, porque la paciente carecía de manifestaciones clínicas compatibles. Se indicó anestesia de conducción con peridural continua y monitorización electrónica que reveló una variabilidad menor de 5 LCF, una frecuencia cardíaca fetal media de 150 latidos por min y una desaceleración variable prolongada (hasta 120 LCF por minuto durante $3 \mathrm{~min}$ ).

Se reevaluó luego de nueva desaceleración (60 LCF por minuto durante $7 \mathrm{~min}$ ) y se encontró 8 a 9 cms de dilatación, presentación cefálica en II plano y LA con grumos de meconio con leve mal olor. Se trasladó inmediatamente a sala de partos con dilatación completa y presentación cefálica en tercer plano.

El parto vaginal ocurrió a las 7:24 h del 11 de mayo (1 h 44 min desde el ingreso). Se obtuvo un recién nacido $(\mathrm{RN})$ de $3.440 \mathrm{~g}$ de sexo masculino, con muy mal olor, muy deprimido con Apgar 1 al minuto y 3 a los $5 \mathrm{~min}$. No se describió presencia de meconio en el parto, ni en la aspiración de las secreciones del RN. En la sangre arterial de cordón se encontró pH 6,9, BE -25 y CO2 35. Ingresó intubado grave a la UCI neonatal, con los diagnósticos: $\mathrm{RN}$ de término adecuado para la edad gestacional, de 40 semanas, asfixia perinatal severa (criterios de la Asociación Americana de Pediatría) y probable infección connatal.

El RN evolucionó siempre grave, con compromiso del SNC, encefalopatía hipóxica isquémica grado III, asociado a shock séptico precoz, con compromiso multiorgánico y necesidad de apoyo ventilatorio y de drogas vasoactivas.

A las 24 h de vida los hemocultivos tomados al nacer fueron positivos para Morganella morganii cambiándose el esquema antibiótico ampicilinasulbactam por cefotaxima, según antibiograma. Los exámenes demostraron: hemograma con leucopenia, proteína C reactiva $129 \mathrm{mg} / \mathrm{L}$, ácido láctico $138 \mathrm{mg} / \mathrm{dL}$. La radiografía de tórax reveló infiltrado parenquimatoso bilateral compatible con bronconeumonía. El escáner y la ecografía cerebral mostraron edema cerebral y hemorragia de fosa posterior izquierda concordante con EEG severamente alterado, en status convulsivo.

El neonato falleció a los 17 días de vida. La autopsia reveló: RN de término, adecuado para la edad gestacional, con signos morfológicos de shock séptico: coagulación intravascular diseminada, infarto hepático, de glándulas suprarrenales y congestión esplénica. Bronconeumonía bilateral descamativa y hemorrágica. Compromiso cerebral con encefalopatía hipóxica-isquémica.

La biopsia placentaria reveló corioamnionitis aguda abscedada, funisitis aguda y perivellositis aguda focal.

La madre evolucionó afebril, sin signos clínicos de infección, pero con cultivo de loquios positivos para Morganella morganii, muestra tomada el primer día de puerperio del fondo de saco vaginal. Se dio de alta hospitalaria a los tres días del parto y se trató durante 5 días con gentamicina $160 \mathrm{mg}$ IM al día. Se controló a los 11 días de puerperio en el policlínico del Centro Diagnóstico Terapéutico y se dio de alta definitiva en buenas condiciones físicas.

\section{DiSCUSIÓN}

El caso clínico presentado corresponde a una sepsis congénita por M morganii y es el primero que se describe en un parto de término, sin rotura prematura de membranas y sin manifestaciones 
clínicas de infección en la madre. Existen 9 casos de sepsis de inicio precoz por $M$ morganii relatados en la literatura y todos se presentaron en partos prematuros ${ }^{5-11}$ con el antecedente de rotura prematura de membranas ${ }^{5-10}$ y en la mayoría de ellos con corioamnionitis clínica ${ }^{5-7,10}$.

El diagnóstico de sepsis neonatal por Morganella morganii se efectuó precozmente a las $24 \mathrm{~h}$ de vida, por manifestaciones clínicas compatibles y por el aislamiento de la bacteria en la sangre del neonato. Es sugestiva la ruta ascendente de Morganella morganii por el cultivo de esta bacteria en los loquios maternos y por los hallazgos histológicos placentarios sugerentes de infección bacteriana ascendente, corioamnionitis aguda abscedada, funisitis aguda y perivellositis aguda focal ${ }^{13,14}$. Es posible suponer que esta infección congénita debió iniciarse antes del desencadenamiento del parto y que contribuyó a su inicio. Esta hipótesis se basa en la brevedad del trabajo de parto en una primípara $(3 \mathrm{~h})$, en la precocidad y gravedad de la sepsis neonatal y en la intensidad de las lesiones placentarias.

El sufrimiento fetal agudo que condujo a la asfixia perinatal severa y a la encefalopatía hipóxica isquémica grave ocurrido en éste y en otros casos asociados con infección bacteriana ascendente, además de la sepsis se puede deber, al compromiso inflamatorio infeccioso del cordón umbilical (funisitis) secundario a la infección e inflamación intraamniótica ${ }^{13-15}$.

El tratamiento antibiótico empírico inicial con ampicilina-sulbactam, fue reemplazado por cefotaxima al conocerse el aislamiento de M morganii y su

\section{REFERENCIAS}

1. O'Hara CM, Brenner FW, Millar JM. Classification, identification, and clinical significance of Proteus, Providencia, and Morganella. Clin Microbiol Rev 2000; 13: 534-46.

2. Falagas ME, Kavvadía PK, Matadakis E, Kofteridis DP, Bliziotis IA, Saloustros E et al. Morganella morganii infections in a general tertiary hospital. Infection 2006; 34: 315-21.

3. LeE I-K, Liu J-W. Clinical characteristics and risk factors for mortality in Morganella morganii bacteremia. J Microbiol Immunol Infect 2006; 39: 328-34.

4. Verhamme KM, De Coster W, De Roo L, De Beenhouwer H, Nollet G, Verbeke J et al. Pathogens in susceptibilidad a cefalosporinas de tercera generación. Es importante señalar que $\mathrm{M}$ morganii es intrínsecamente resistente a cefalosporinas de primera generación, aminopenicilinas y a otros antibióticos como polimixina $\mathrm{B}$, nitrofuranos $\mathrm{y}$, que su resistencia a antibióticos ß-lactámicos es mediada por una ß-lactamasa cromosomal inducible del tipo AmpC grupo 1/clase $C$ que no es inhibida por sulbactam ${ }^{16-17}$. El antibiograma de esta cepa también demostró susceptibilidad a trimetropim-sulfametoxazol, gentamicina, amikacina y ciprofloxacina y resistencia a ampicilina y cefalotina.

Para sospechar la existencia de una infección intraamniótica subclínica causada por bacterias de escasa prevalencia en un embarazo de término, nos parece conveniente que se tengan presentes las siguientes variables obstétricas: trabajo de parto acelerado, presencia de meconio y especialmente si tiene mal olor, desaceleraciones en la monitorización electrónica y perfil biofísico fetal ultrasonográfico alterado.

La prevención de la infección neonatal por esta u otra bacteria de inusual ocurrencia se basa en la pesquisa y tratamiento oportunos de toda infección cervicovaginal durante el embarazo.

En resumen se trata de un caso excepcional de infección congénita muy grave por Morganella morganii en un parto de término de curso muy rápido, sin rotura prematura de membranas y que no dio ninguna evidencia clínica de su existencia durante la hora y 44 min de duración del trabajo de parto en el hospital. Condujo inexorablemente a la muerte neonatal por una sepsis severa y daño neurológico asociado.

early-onset and late-onset intensive care unit-acquired pneumonia. Infect Control Hosp Epidemiol 2007; 28: 389-97.

5. Johnson JR, Feingold M. Case of chorioamnionitis in an immunocompetent woman caused by Morganella morganii. J Matern Fetal Med 1998; 7: 13-4.

6. Rowen JL, LÓPez SM. Morganella morganii early onset sepsis. Pediatr Infect Dis J 1998; 17: 1176-7.

7. Ranu SS, Valencia GB, Piecuch S. Fatal early onset infection in an extremely low birth weight infant due to Morganella morganii. J Perinatol 1999; 19: 533-5.

8. Casanova-Roman M, Sánchez-Porto A, Casanova-BelliDo M. Early-onset neonatal sepsis caused by vertical transmission of Morganella morganii. Scand J Infect Dis 2002; 34: 534-5. 
9. DutTa S, Narang A. Early onset neonatal sepsis due to Morganella morganii. Indian Pediatrics 2004; 41: 1155-7.

10. Boussemart T, Piet-Duroux $S$, Manouana $M$, Azi M, Perez JM, Port-Lis M. Morganella morganii and early-onset neonatal infection. Arch Pediatr 2004; 11: 37-9.

11. Sinha AK, Kempley ST, Price E, Sharma BK, Livermore DM. Early onset Morganella morganii sepsis in a newborn infant with emergence of cephalosporin resistance caused by depression of AmpC betalactamase production. Pediatr Infect Dis J 2006; 25 : 376-7.

12. SALEN PN, Eppes S. Morganella morganii: a newly reported, rare cause of neonatal sepsis. Acad Emerg Med 1997; 4: 711-4.

13. Ovalle A, Martínez ma, Kakarieka me, Gómez R, Torres J, Fuentes A et al. Histopatología de la placenta en la rotura prematura de membranas de pretérmino. Relación con la microbiología aislada y con los resultados maternoneonatales. Rev Méd Chile 1998; 126: 930-42.

14. Ovalle A, Gómez R, Martínez Ma, Kakarieka E, Fuentes A, Aspillaga C ET al. Invasión microbiana de la cavidad amniótica en la rotura de membranas de pretérmino. Resultados materno-neonatales y patología placentaria según microorganismo aislado. Rev Méd Chile 2005; 133: 51-61.

15. Murthy V, Kennea NL. Antenatal infection/inflammation and fetal tissue injury. Best Pract Res Clin Obstet Gynaecol 2007; 21: 479-89.

16. Bush K, Jacoby GA, Medeiros AA. A functional classification scheme of $B$-lactamases and its correlation with molecular structure. Antimicrob Agents Chemother 1995; 39: 1211-33.

17. Poirel L, Guibert M, Girlich D, NaAs T, Nordmann P. Cloning, sequence analyses, expression, and distribution of ampC-ampR from Morganella morganii clinical isolates. Antimicrob Agents Chemother 1999; 43: 769-76. 